\title{
Anafilaxia em Portugal: 10 anos de Registo Nacional da SPAIC 2007-20I7
}

\section{Anaphylaxis in Portugal: 10-year SPAIC National Survey 2007-2017}

\author{
Data de receção / Received in: 14/12/2019 \\ Data de aceitação / Accepted for publication in: 16/12/2019
}

Rev Port Imunoalergologia 2019;27 (4):289-307

Ângela Gasparl, Natacha Santos², Emília Faria ${ }^{3}$, Rita Câmara ${ }^{4}$, Rodrigo Rodrigues-Alves ${ }^{5}$, Isabel Carrapatoso ${ }^{3}$, Eva Gomes ${ }^{6}$, Ana Margarida Pereira ${ }^{7}$, Leonor Carneiro-Leão ${ }^{8}$, Mário Morais-Almeida9, Luís Delgado ${ }^{8,10}$, Elisa Pedro", Manuel Branco-Ferreira" ${ }^{11,12}$, Grupo de Interesse de "Anafilaxia e Doenças Imunoalérgicas Fatais" da SPAIC

I Serviço de Imunoalergologia, Hospital da Luz, Lisboa

2 Serviço de Imunoalergologia, Centro Hospitalar Universitário do Algarve

${ }^{3}$ Serviço de Imunoalergologia, Hospitais da Universidade de Coimbra, Centro Hospitalar e Universitário de Coimbra

${ }^{4}$ Unidade de Imunoalergologia, Hospital Dr. Nélio Mendonça, Funchal

${ }^{5}$ Unidade de Imunoalergologia, Hospital Divino Espírito Santo, Ponta Delgada

${ }^{6}$ Unidade de Imunoalergologia, Hospital Maria Pia, Centro Hospitalar do Porto

${ }^{7}$ Unidade de Imunoalergologia, Hospital CUF Porto e Instituto CUF Porto

${ }^{8}$ Serviço de Imunoalergologia, Centro Hospitalar São João, Porto

${ }^{9}$ Centro de Imunoalergologia, Hospital CUF Descobertas, Lisboa

${ }^{10}$ Serviço de Imunologia Básica e Clínica, Departamento de Patologia, Faculdade de Medicina da Universidade do Porto

" Serviço de Imunoalergologia, Hospital de Santa Maria, Centro Hospitalar Lisboa Norte

${ }^{12}$ Clínica Universitária de Imunoalergologia, Faculdade de Medicina da Universidade de Lisboa

\section{RESUMO}

Introdução: A anafilaxia é a forma mais grave de doença alérgica; no entanto, a real prevalência em diferentes grupos populacionais é incerta por ausência de registos adequados desta entidade potencialmente fatal. Objetivos: Contribuir para melhorar o conhecimento epidemiológico e a abordagem da anafilaxia no nosso país. Métodos: Durante um período de 10 anos (2007 a 2017) foi implementado um sistema de notificação nacional de anafilaxia focalizado na notificação voluntária por clínicos com diferenciação em patologia imunoalérgica. Foram incluídas notificações de anafilaxia de 1783 doentes. Foi efetuada caracterização detalhada sobre etiopatogenia, manifestações e

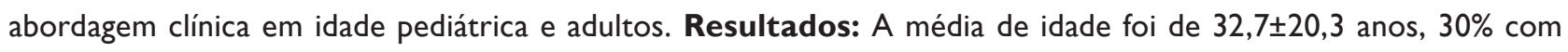
idade inferior a 18 anos e 10\% de idade pré-escolar. A relação de género feminino/masculino foi de I,4. A maioria (68\%) tinha antecedentes pessoais de doença alérgica, 33\% com asma. A média de idade do primeiro episódio foi de $27,5 \pm 20,4$ anos (com variação entre I mês e 88 anos). As principais causas da anafilaxia foram os alimentos (48\%), os fármacos 
Ângela Gaspar, Natacha Santos, Emília Faria, Rita Câmara, Rodrigo Rodrigues-Alves, Isabel Carrapatoso, Eva Gomes, Ana Margarida Pereira, Leonor Carneiro-Leão, Mário Morais-Almeida, Luís Delgado, Elisa Pedro, Manuel Branco-Ferreira, Grupo de Interesse de "Anafilaxia e Doenças Imunoalérgicas Fatais" da SPAIC

(37\%), primeira causa nos adultos, e os venenos de himenópteros (7\%). Os principais alimentos foram o marisco (crustáceos e/ou moluscos) $27 \%$, frutas frescas $17 \%$, leite $16 \%$, frutos secos $15 \%$, peixe $8 \%$, ovo $7 \%$, amendoim $7 \%$ e sementes $3 \%$. Os principais fármacos foram os AINE, $43 \%$, os antibióticos, $39 \%$, e os agentes anestésicos, $6 \%$. Outras causas identificadas foram a anafilaxia induzida pelo exercício, $3 \%$, a anafilaxia induzida pelo látex, a anafilaxia induzida pelo frio e a anafilaxia idiopática, $2 \%$, entre outras. Houve predomínio de manifestações mucocutâneas (96\%), seguido de respiratórias $(82 \%)$ e cardiovasculares (36\%). A maioria dos doentes $(80 \%)$ foi admitida em serviço de urgência, sendo que apenas $43 \%$ recebeu tratamento com adrenalina. Ocorreu recorrência da anafilaxia em $41 \%$ dos doentes (com $\geq 3$ episódios de anafilaxia em $21 \%$ ), tendo sido o dispositivo autoinjetor de adrenalina utilizado por $7 \%$ dos doentes. Conclusões: Os alimentos foram a causa mais frequente de anafilaxia em Portugal, sobretudo em idade pediátrica. Os fármacos foram os principais desencadeantes de anafilaxia na idade adulta. Destaca-se o subtratamento com adrenalina e a recorrência de anafilaxia, apontando para a necessidade de serem implementadas medidas estratégicas e educativas de forma a melhorar a abordagem diagnóstica e terapêutica da anafilaxia.

Palavras-chave: Adrenalina, anafilaxia, etiologia, notificação, registo português.

\section{ABSTRACT}

Background: Anaphylaxis is the most severe manifestation of an allergic disease. However, the actual prevalence in different population groups is uncertain due to the lack of adequate records of this potentially fatal entity. Objectives: Contribute to the improvement on epidemiological knowledge and anaphylaxis management in our country. Methods: Over a 10-year period (2007-2017) a national anaphylaxis reporting system was implemented, focused on voluntary reporting by clinicians with differentiation in immuno-allergic diseases. Reports of anaphylaxis from 1783 patients were included. Detailed characterization of etiopathogenesis, manifestations and clinical approach was performed in pediatric and adult ages. Results: The average age was $32.7 \pm 20.3$ years, with $30 \%$ under 18 and $10 \%$ of preschool age. The female / male gender ratio was 1.4 . Most (68\%) had a personal history of allergic disease, 33\% with asthma. The average age of the first episode was $27.5 \pm 20.4$ years (ranging from I month to 88 years). The main causes of anaphylaxis were food (48\%), drugs (37\%) (the first cause in adults) and hymenoptera venom (7\%). The main foods were shellfish (crustaceans and/or mollusks) $27 \%$, fresh fruits $17 \%$, milk $16 \%$, tree nuts $15 \%$, fish $8 \%$, egg $7 \%$, peanut $7 \%$ and seeds $3 \%$. The main drugs were NSAID $43 \%$, antibiotics $39 \%$ and anesthetic agents $6 \%$. Other causes identified were exercise-induced anaphylaxis 3\%, latex-induced anaphylaxis, cold-induced anaphylaxis and idiopathic anaphylaxis $2 \%$, among others. There was a predominance of mucocutaneous (96\%) manifestations, followed by respiratory (82\%) and cardiovascular (36\%) manifestations. Most patients (80\%) were admitted to the emergency department, and only $43 \%$ received epinephrine treatment. Anaphylaxis recurred in $41 \%$ of patients ( $21 \%$ with $\geq 3$ episodes of anaphylaxis). The adrenaline autoinjector device was used by $7 \%$ of patients. Conclusions: Food was the most frequent cause of anaphylaxis in Portugal, especially at pediatric age. Drugs were the main triggers of anaphylaxis in adults. We highlight the undertreatment with epinephrine and the recurrence of episodes, pointing to the need to implement strategic and educational measures to improve the therapeutic and diagnostic approach of anaphylaxis.

Key-words: Anaphylaxis, epinephrine, etiology, notification, Portuguese survey. 


\section{INTRODUÇÃO}

A anafilaxia é uma emergência médica por excelência tratando-se de uma reação de hipersensibilidade sistémica grave e potencialmente fatal'. Segundo a nomenclatura da World Allergy Organisation $(\mathrm{WAO})^{2}$, a anafilaxia pode ser desencadeada por mecanismos imunológicos (anafilaxia alérgica) mediados por imunoglobulina $\mathrm{E}$ ( $\mathrm{lgE}$ ) (anafilaxia alérgica IgE mediada), por outros mecanismos imunológicos (anafilaxia alérgica não lgE mediada), ou por mecanismos não imunológicos (anafilaxia não alérgica). É um assunto prioritário na agenda de vários sistemas de saúde e sociedades científicas, de âmbito nacional e internacional, assumindo grande preocupação a falta de reconhecimento e a deficiente abordagem, nomeadamente em situações de emergência destes quadros de extrema gravidade.

A procura de uma definição prática e baseada em critérios clínicos, independentemente dos mecanismos subjacentes, permitindo facilitar o reconhecimento quer a nível de medicina hospitalar, quer a nível de ambulatório, foi um dos principais objetivos das sociedades científicas que pretenderam uniformizar a abordagem diagnóstica e terapêutica desta entidade. Em 2006 foram revistos e publicados por Sampson et al. ${ }^{3}$ os critérios para o diagnóstico de anafilaxia, que incluíram, para além de sintomas mucocutâneos, respiratórios e cardiovasculares, a ocorrência de sintomas gastrintestinais aquando da exposição ao agente causal, permitindo a uniformização da definição de anafilaxia. Estes critérios, inicialmente propostos pela American Academy of Allergy, Asthma \& Immunology (AAAAI), foram posteriormente aceites e recomendados pela European Academy of Allergy and Clinical Immunology (EAACI) ${ }^{4}$ e pela WAO'.

A epidemologia da anafilaxia pode centrar-se na recolha de dados de mortalidade por esta entidade em casuísticas de doentes observados em ambulatório hospitalar especializado ou de doentes internados, dados de admissões hospitalares ou de observações em serviços de urgência ou de emergência e, finalmente, em amostras da população geral.

A prevalência de anafilaxia durante a vida é de 0,05 a $2 \%{ }^{5}$, apontando uma revisão de estudos europeus para uma prevalência estimada de $0,3 \%$, ou seja, I em cada 300 indivíduos sofre um episódio de anafilaxia durante a sua vida ${ }^{6}$. A incidência de anafilaxia foi estimada em estudos populacionais entre 8,4 a 50 por cada 100000 indivíduos/ano $0^{5,7}$, com uma mortalidade de I a 3 casos por cada milhão por $a_{n}{ }^{8}$, o que representa cerca de $2 \%$ dos casos de anafilaxia.

Tem-se verificado um aumento da prevalência de anafilaxia ao longo do tempo, sobretudo em idade pediátrica ${ }^{6,8}$ e particularmente em crianças em idade pré-escolar $^{6,9}$, sendo os alimentos a causa de anafilaxia mais frequentemente implicada nesta faixa etária ${ }^{6,8,9}$. Os fármacos são os principais desencadeantes de anafilaxia na idade adulta e particularmente em idades superiores a 65 anos, existindo fatores geográficos que influenciam a incidência da anafilaxia a diferentes classes de fármacos relacionados com o padrão de prescriçãol,10.

Em Portugal não são conhecidas até à data taxas de prevalência ou incidência de anafilaxia na população em geral. A nível nacional apenas existem dados de casuísti$\mathrm{ca}$, quer de consulta quer de internamento, que refletem provavelmente por defeito os números globais da população. Num estudo realizado em 2006, Morais-Almeida et al. reportaram uma prevalência de anafilaxia de I,34\% em doentes que recorreram durante um ano ao ambulatório de um serviço de Imunoalergologia na região de Lisboa, sendo metade dos doentes em idade pediátrica"'. A maioria apresentava anafilaxia induzida por alimentos (59\%), seguida dos fármacos em $17 \%$ e do látex em $13 \%$. Numa avaliação posterior, em 201I, também na região de Lisboa, Gaspar et al. reportaram uma prevalência de anafilaxia de I,76\% considerando a população pediátrica com menos de 18 anos $^{12}$. A maioria apresentava anafilaxia induzida por alimentos com $84 \%$, seguida dos fármacos com $8 \%$. Outro estudo, também efetuado num ambulatório de um serviço de Imunoalergologia, Silva et al. re- 
Ângela Gaspar, Natacha Santos, Emília Faria, Rita Câmara, Rodrigo Rodrigues-Alves, Isabel Carrapatoso, Eva Gomes, Ana Margarida Pereira, Leonor Carneiro-Leão, Mário Morais-Almeida, Luís Delgado, Elisa Pedro, Manuel Branco-Ferreira, Grupo de Interesse de "Anafilaxia e Doenças Imunoalérgicas Fatais" da SPAIC

portaram 73 casos de anafilaxia numa retrospetiva de 9 anos de seguimento num hospital pediátrico do Porto ${ }^{13}$. De entre os estudos nacionais publicados destaca-se ainda o de Botelho et al., que efetuaram uma análise retrospetiva dos doentes internados no período de 10 anos num serviço de Imunoalergologia na região do Porto e obtiveram uma frequência de anafilaxia de $0,012 \%{ }^{14}$. Os principais agentes indutores de reação anafilática foram fármacos $(66 \%)$, meios de contraste (19\%), alimentos (I3\%) e veneno de himenópteros (2\%).

A real prevalência de anafilaxia em Portugal é desconhecida, pela ausência do registo sistemático destes casos, nomeadamente de um registo de notificação obrigatória nacional; no entanto, é consensual o aumento crescente de casos observados nos últimos anos.

Com esta iniciativa pretendeu-se contribuir para o meIhor conhecimento epidemiológico da anafilaxia no nosso país focalizado na notificação voluntária por clínicos com diferenciação em patologia imunoalérgica de quadros de anafilaxia observados em consultas de Imunoalergologia.

\section{MATERIAL E MÉTODOS}

Durante um período de dez anos (2007 a 2017) foi implementado pela Sociedade Portuguesa de Alergologia e Imunologia Clínica (SPAIC) um sistema de notificação de anafilaxia de âmbito nacional.

O diagnóstico de anafilaxia foi definido de acordo com os critérios publicados pelos consensos AAAAI, EAACI e WAO quando na presença de pelo menos um dos três critérios clínicos descritos no Anexo $1^{3}$.

Todos os médicos com diferenciação em Imunoalergologia e sócios da SPAIC foram convidados a participar neste projeto, tendo sido solicitada a notificação voluntária de todos os casos observados de anafilaxia ("pelo menos um episódio de reação sistémica grave") através do preenchimento de um questionário. A notificação foi disponibilizada por carta, fax, e-mail e on-line no website da SPAIC (www.spaic.pt). Todas as notificações rece- bidas foram avaliadas e validadas por elementos do Grupo de Interesse de "Anafilaxia e Doenças Imunoalérgicas Fatais" (GANDALF) da SPAIC, e em caso de necessidade foram solicitados esclarecimentos aos notificadores.

\section{População}

Foram obtidos os questionários correspondentes a 1783 doentes com história de anafilaxia, notificados por 82 médicos sócios da SPAIC e provenientes na sua maioria de serviços/unidades de Imunoalergologia nacionais.

\section{Questionário}

A todos os doentes foi efetuado um questionário, indicado no Anexo 2, para caracterização clínica da situação, avaliando os seguintes parâmetros:

- dados demográficos, incluindo idade, género e concelho de residência;

- antecedentes pessoais de asma ou outra patologia alérgica;

- caracterização do fator causal implicado;

- data da primeira reação anafilática e descrição pormenorizada das manifestações clínicas, mucocutâneas, respiratórias, gastrintestinais e cardiovasculares;

- número de episódios de anafilaxia ocorridos e agentes envolvidos;

- descrição da terapêutica efetuada, incluindo informação sobre o uso de adrenalina, necessidade de recurso a urgência hospitalar ou internamento hospitalar;

- posse e utilização de dispositivo autoinjetor de adrenalina.

\section{Análise estatística}

Os resultados são apresentados na forma de frequências e percentagens relativamente ao número total de respostas validadas. Variáveis quantitativas de distribuição normal são expressas em média \pm desvio-padrão. Variáveis não normalmente distribuídas são expressas 
como mediana (limites mínimo e máximo). Foi utilizado o teste de qui-quadrado e o cálculo do odds ratio (OR) com intervalo de confiança a 95\% (IC) para testar associação entre variáveis qualitativas e considerado significativo um $\mathrm{p}<0,05$ (IBM $^{\circledR}$ SPSS ${ }^{\circledR}$ Statistics version 23 ).

\section{RESULTADOS}

No período referido foram reportados 1783 doentes com anafilaxia. Relativamente ao concelho de residência, a distribuição foi: 19,2\% na região Norte, 12,3\% na região Centro, $52,6 \%$ na região Sul e $15,4 \%$ nas regiões autónomas dos Açores e da Madeira, correspondendo respetivamente a $6,2 \%$ e $9,2 \%$. Nove doentes $(0,5 \%)$ encontravam-se atualmente a residir fora de Portugal: 2 em Angola, I em Cabo Verde, I na China, I nos Estados Unidos, I na Guiné, I em Moçambique, I no Qatar e I no Reino Unido.

Os doentes apresentavam uma média de idade de 32,7 $\pm 20,3$ anos, com idades mínima de 3 meses e máxima de 90 anos. Quinhentos e trinta e três doentes (30\%) tinham idade inferior a 18 anos e 1250 (70\%) eram adultos. A distribuição por grupo etário dos doentes foi: $183 \mathrm{com}$ $<6$ anos (10\%), 350 entre 6 e 17 (20\%), 413 entre 18 e 34 (23\%), 729 entre 35 e 64 (4l\%) e 108 com $\geq 65$ anos (6\%).

Verificou-se um predomínio do género feminino, 58\% para $42 \%$ do género masculino, com uma relação feminino/masculino de I,4. Nos doentes de idade inferior a 18 anos, pelo contrário, observou-se um predomínio do género masculino em relação ao feminino (I,6:I). Nos adultos acentuou-se o predomínio do género feminino, com uma relação feminino/masculino de I,9.

Tinham antecedentes pessoais de doença alérgica $68 \%$. Tinham asma como comorbilidade $33 \%$, rinite alérgica $58 \%$, eczema atópico $11 \%$ e conjuntivite alérgica $8 \%$, cinco doentes tinham esofagite eosinofílica ( 3 adultas e 2 crianças), um adulto mastocitose sistémica e uma adulta angioedema hereditário.
A média de idade do primeiro episódio de anafilaxia foi de 27,5 $\pm 20,4$ anos, com uma idade mínima de I mês e uma idade máxima de 88 anos, respetivamente um lactente com anafilaxia por proteínas do leite de vaca e um idoso com anafilaxia ao ácido acetilsalicílico (AAS). Em 663 doentes (37\%) o primeiro episódio de anafilaxia ocorreu com idade inferior a 18 anos e em 71 (4\%) com idade $\geq 65$ anos. Salienta-se o facto de em 352 doentes (20\%) o primeiro episódio de anafilaxia ter ocorrido em idade pré-escolar (abaixo dos 6 anos) e em I5I crianças (8\%) no primeiro ano de vida.

\section{Manifestações clínicas}

Relativamente às manifestações clínicas, $96 \%$ dos doentes apresentaram sintomas mucocutâneos, $82 \%$ respiratórios, $36 \%$ cardiovasculares e $29 \%$ referiram queixas gastrintestinais. Conforme ilustrado na Figura I, 32\% tiveram edema laríngeo e 15\% perda de conhecimento.

Houve predomínio da associação de sintomatologia mucocutânea e respiratória, sendo que em $78 \%$ ocorreram concomitantemente estes sintomas. Em 66 doentes (4\%) não existiram manifestações mucocutâneas. $\bigcirc$ número de sintomas respiratórios foi mais elevado nos doentes com asma do que nos não asmáticos [( $90 \%$ vs. $78 \%$,

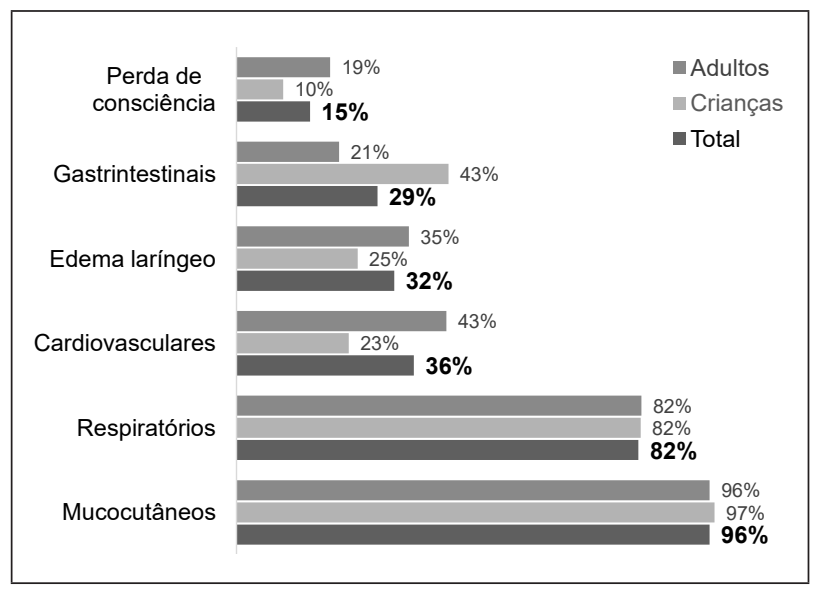

Figura I. Tipo de manifestações clínicas no primeiro episódio de anafilaxia nos 1783 doentes reportados e sua distribuição por grupo etário (\%), nas crianças $<18$ anos e nos adultos com $\geq 18$ anos 
Ângela Gaspar, Natacha Santos, Emília Faria, Rita Câmara, Rodrigo Rodrigues-Alves, Isabel Carrapatoso, Eva Gomes, Ana Margarida Pereira, Leonor Carneiro-Leão, Mário Morais-Almeida, Luís Delgado, Elisa Pedro, Manuel Branco-Ferreira, Grupo de Interesse de "Anafilaxia e Doenças Imunoalérgicas Fatais" da SPAIC

$\mathrm{P}<0,0 \mathrm{I}, \mathrm{OR}=2,6(\mathrm{IC}=1,9-3,6)]$. Mil e quinze doentes $(57 \%)$ tiveram manifestações cardiovasculares, edema laríngeo ou perda de consciência, sendo que o diagnóstico de asma não foi fator de risco para a ocorrência destes sintomas.

O número de sintomas gastrintestinais foi mais elevado nas crianças do que nos adultos [( $43 \%$ vs. $21 \%$, $\mathrm{P}<0,0 \mathrm{I}, \mathrm{OR}=2,9(\mathrm{IC}=2,3-3,6)]$, sendo mais elevado $(51 \%)$ em crianças em idade pré-escolar.

\section{Recurso a urgência e tratamento realizado}

Mil quatrocentos e vinte e seis doentes $(80 \%)$ foram admitidos em serviço de urgência hospitalar e, em $20 \%$ dos casos, motivaram necessidade de internamento hospitalar. Nenhuma destas reações foi fatal, tendo regredido com a terapêutica instituída.

Relativamente ao tipo de tratamento efetuado para resolução da reação anafilática, apenas $43 \%$ dos doentes receberam tratamento com adrenalina.

O diagnóstico de asma não foi fator de risco para o recurso ao serviço de urgência nem para a administração de adrenalina.

\section{Recorrência e utilização de adrenalina autoinjetável}

Em 1049 doentes (59\%) foi prescrito para o ambulatório dispositivo autoinjetor de adrenalina; a prescrição foi significativamente inferior nos casos de anafilaxia induzida por fármacos comparativamente a outras causas (II\% vs. $87 \%, p<0,0 I$ ).

Em 728 doentes (4l\%) houve recorrência da anafilaxia: 2 episódios em 360 doentes (20\%), 3 episódios em 173 (10\%), 4 em 93 (5\%) e $\geq 5$ em 102 (6\%). Cento e dezanove $(7 \%)$ necessitaram de usar o dispositivo autoinjetor de adrenalina nas reações subsequentes.

A utilização do dispositivo autoinjetor de adrenalina foi mais frequente nos doentes com asma do que nos não asmáticos $[(10 \%$ vs. $6 \%, \mathrm{p}<0,0 \mathrm{I}, \mathrm{OR}=\mathrm{I}, 7(\mathrm{IC}=\mathrm{I}, 2-2,5)]$.

\section{Estudo etiológico}

A frequência relativa das várias etiologias associadas a anafilaxia segundo o grupo etário, em idade pediátrica e adultos, está representada no Quadro I. Trinta e sete doentes apresentaram mais de uma causa de anafilaxia, correspondendo a um total de 1819 notificações de diferentes grupos de causas distintas envolvidas.

A principal causa de anafilaxia, presente em 859 doentes (48\%), foi a anafilaxia induzida por alimentos, surgindo a maioria dos casos em idade pediátrica $(77 \%$ nas crianças com idade inferior a 18 anos) - Quadro I. A anafilaxia induzida por fármacos representa a segunda causa (37\%), com maior frequência nos adultos (48\%). A anafilaxia por picada de insetos foi a terceira causa, ocorrendo em $7 \%$, também com maior frequência na idade adulta (9\%).

Outras causas identificadas foram a anafilaxia induzida pelo exercício em $3 \%$, sendo 44 dos 45 casos de anafilaxia induzida pelo exercício dependente de alimentos (AIEDA), e a anafilaxia induzida pelo látex (por contacto com látex ou em contexto de síndrome látex-frutos), a anafilaxia induzida pelo frio e a anafilaxia idiopática em $2 \%$ dos casos. Em sete doentes o agente causal implicado foram outras causas mais raras, como a imunoterapia específica em 4 casos (imunoterapia para ácaros em 2 crianças, para pólenes numa adulta e veneno de abelha em fase de manutenção num adulto), a inalação de alergénios animais, como epitélio de cavalo, em dois doentes, e a contaminação de alimento cru com parasita (Anisakis simplex) numa adulta.

Os alimentos implicados nos doentes reportados com anafilaxia por alergia alimentar encontram-se discriminados no Quadro 2, sendo referida a sua distribuição relativa nos grupos etários com menos de 18 anos e com idade $\geq 18$ anos. A maioria destes doentes tinha antecedentes pessoais de alergia (83\%), e tinham asma como comorbilidade $44 \%$.

O marisco (crustáceos e/ou moluscos) foi a primeira causa de anafilaxia induzida por alimentos (27\%), com maior frequência nos adultos. Os crustáceos (sobretudo o camarão) foram os principais responsáveis. Nos moluscos destaca-se a particularidade geográfica dos casos de anafilaxia à lapa terem sido sobretudo reportados na região da Madeira. 
Quadro I. Etiologia dos episódios de anafilaxia e sua distribuição por grupo etário (n, \%), nas crianças e adolescentes com < 18 anos e nos adultos com $\geq 18$ anos

\begin{tabular}{|c|c|c|c|}
\hline Etiologia da anafilaxia & $\begin{array}{l}\text { Total de doentes } \\
n=1783(\%)\end{array}$ & $\begin{array}{l}<18 \text { anos } \\
n=533(\%)\end{array}$ & $\begin{array}{r}\geq 18 \text { anos } \\
n=1250(\%)\end{array}$ \\
\hline Anafilaxia induzida por alimentos & $\begin{array}{c}859 \\
(48,2 \%)\end{array}$ & $\begin{array}{c}411 \\
(77,1 \%)\end{array}$ & $\begin{array}{c}448 \\
(35,8 \%)\end{array}$ \\
\hline Anafilaxia induzida por fármacos & $\begin{array}{c}659 \\
(36,9 \%)\end{array}$ & $\begin{array}{c}57 \\
(10,7 \%)\end{array}$ & $\begin{array}{c}602 \\
(48,2 \%)\end{array}$ \\
\hline Anafilaxia por picada de insetos & $\begin{array}{c}132 \\
(7,4 \%)\end{array}$ & $\begin{array}{c}24 \\
(4,5 \%)\end{array}$ & $\begin{array}{c}108 \\
(8,6 \%)\end{array}$ \\
\hline $\begin{array}{l}\text { Anafilaxia induzida pelo exercício } \\
\text { (dependente de alimentos - 44) }\end{array}$ & $\begin{array}{c}45 \\
(2,5 \%)\end{array}$ & $\begin{array}{c}12 \\
(2,3 \%)\end{array}$ & $\begin{array}{c}33 \\
(2,6 \%)\end{array}$ \\
\hline Anafilaxia induzida pelo látex & $\begin{array}{c}41 \\
(2,3 \%)\end{array}$ & $\begin{array}{c}6 \\
(1,1 \%)\end{array}$ & $\begin{array}{c}35 \\
(2,8 \%)\end{array}$ \\
\hline Anafilaxia induzida pelo frio & $\begin{array}{c}40 \\
(2,2 \%)\end{array}$ & $\begin{array}{c}21 \\
(3,9 \%)\end{array}$ & $\begin{array}{c}19 \\
(1,5 \%)\end{array}$ \\
\hline Anafilaxia idiopática & $\begin{array}{c}36 \\
(2,0 \%)\end{array}$ & $\begin{array}{c}5 \\
(0,9 \%)\end{array}$ & $\begin{array}{c}31 \\
(2,5 \%)\end{array}$ \\
\hline $\begin{array}{l}\text { Outras causas } \\
\text { (imunoterapia específica - 4; epitélio de cavalo - 2; } \\
\text { Anisakis simplex - I) }\end{array}$ & $\begin{array}{c}7 \\
(0,4 \%)\end{array}$ & $\begin{array}{c}3 \\
(0,6 \%)\end{array}$ & $\begin{array}{c}4 \\
(0,3 \%)\end{array}$ \\
\hline
\end{tabular}

O leite de vaca foi a terceira causa de anafilaxia induzida por alimentos, mas foi o principal alimento implicado (32\%) no grupo etário pediátrico.

Os frutos frescos foram a segunda causa (17\%) de anafilaxia alimentar, com destaque particular para as frutas rosáceas (sobretudo o pêssego) e o kiwi. Destaca-se o facto de em muitos casos reportados de anafilaxia a frutas rosáceas ter sido referida pelos notificadores a identificação de sensibilização a lipid transfer proteins (LTP).

Outros alimentos implicados foram, por ordem decrescente de frequência, os frutos secos, o peixe, o ovo, o amendoim, as sementes, os cereais e as carnes de aves e de mamíferos, entre outros. $\mathrm{Na}$ anafilaxia alimentar a carnes, destaque para três casos de anafilaxia a carnes vermelhas, com identificação referida pelos notificadores de sensibilização a galactose-alfa-l,3-galactose (alfa-gal).

De entre as outras causas, destaque para sete casos de pancake síndrome (anafilaxia induzida por farinha con- taminada por ácaros), com a particularidade de todos terem sido reportados na região dos Açores.

Em termos da distribuição por grupo etário das causas de anafilaxia alimentar, como verificado para o leite de vaca, ocorreu um predomínio de casos de anafilaxia por ovo e por amendoim nas crianças. Pelo contrário, para os frutos secos e para o peixe, o número de casos reportado em idade pediátrica e em adultos foi semelhante. $\mathrm{Na}$ anafilaxia alimentar a peixe, destaque também para as particularidades geográficas relacionadas com os peixes implicados.

Os fármacos implicados nos 659 doentes reportados com anafilaxia induzida por fármacos encontram-se discriminados no Quadro 3, sendo referida a sua distribuição relativa nos grupos etários com menos de 18 anos e com idade $\geq 18$ anos. A maioria destes doentes tinha antecedentes pessoais de alergia (55\%), e tinham asma como comorbilidade $22 \%$. As principais causas de anafilaxia a fármacos foram os anti-inflamatórios não esteroides 
Ângela Gaspar, Natacha Santos, Emília Faria, Rita Câmara, Rodrigo Rodrigues-Alves, Isabel Carrapatoso, Eva Gomes, Ana Margarida Pereira, Leonor Carneiro-Leão, Mário Morais-Almeida, Luís Delgado, Elisa Pedro, Manuel Branco-Ferreira, Grupo de Interesse de "Anafilaxia e Doenças Imunoalérgicas Fatais" da SPAIC

Quadro 2. Causas de anafilaxia alimentar, e sua distribuição por grupo etário (n, \%), nas crianças e adolescentes com < 18 anos e nos adultos com $\geq 18$ anos

\begin{tabular}{|c|c|c|c|}
\hline Etiologia da anafilaxia por alimentos & $\begin{array}{c}\text { Total de } \\
\text { doentes } \\
n=859(\%)\end{array}$ & $\begin{array}{l}<18 \text { anos } \\
n=41 \mid(\%)\end{array}$ & $\begin{array}{l}\geq 18 \text { anos } \\
n=448(\%)\end{array}$ \\
\hline 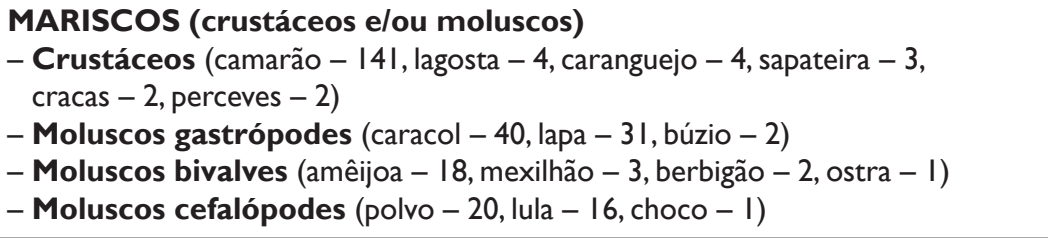 & $\begin{array}{c}230 \\
(26,8 \%)\end{array}$ & $\begin{array}{c}53 \\
(12,9 \%)\end{array}$ & $\begin{array}{c}177 \\
(39,5 \%)\end{array}$ \\
\hline $\begin{array}{l}\text { FRUTAS FRESCAS } \\
\text { - Rosáceas (pêssego }-4 I \text {, maçã }-2 \text { I, pêra }-8 \text {, ameixa }-7 \text {, cereja }-3 \text {, ginja }-2 \text {, } \\
\text { alperce }-1 \text {, framboesa }-1 \text {, morango }-I \text { ) } \\
\text { - Outras (kiwi }-38 \text {, banana }-12 \text {, uva }-1 \mathrm{I} \text {, manga }-6 \text {, melão }-6 \text {, ananás }-5 \text {, } \\
\text { maracujá }-5 \text {, figo }-4 \text {, papaia }-4 \text {, abacate }-3 \text {, coco }-3 \text {, lichia }-2 \text {, meloa }-1 \text {, } \\
\text { tâmara }- \text { I) }\end{array}$ & $\begin{array}{l}145 \\
(16,9 \%)\end{array}$ & $\begin{array}{c}45 \\
(10,9 \%)\end{array}$ & $\begin{array}{c}100 \\
(22,3 \%)\end{array}$ \\
\hline $\begin{array}{l}\text { LEITE } \\
\text { (leite de vaca - 136, leite de cabra - 4, leite de ovelha - I) }\end{array}$ & $\begin{array}{c}139 \\
(16,2 \%)\end{array}$ & $\begin{array}{c}130 \\
(31,6 \%)\end{array}$ & $\begin{array}{c}9 \\
(2,0 \%)\end{array}$ \\
\hline $\begin{array}{l}\text { FRUTOS SECOS } \\
\text { (noz }-43 \text {, caju }-21 \text {, avelã }-16 \text {, pinhão - 16, amêndoa - 16, pistáchio - 7) }\end{array}$ & $\begin{array}{l}127 \\
(14,8 \%)\end{array}$ & $\begin{array}{c}66 \\
(16,1 \%)\end{array}$ & $\begin{array}{c}61 \\
(13,6 \%)\end{array}$ \\
\hline $\begin{array}{l}\text { PEIXES } \\
\text { (bacalhau - I5, pescada }-14 \text {, atum }-6 \text {, sardinha }-6 \text {, peixe-espada }-4 \text {, congro }-3 \text {, } \\
\text { dourada }-3 \text {, gaiado }-3 \text {, linguado }-3 \text {, pargo }-3 \text {, salmão }-3 \text {, bodião }-2 \text {, peixe- } \\
\text { vermelhão }-2 \text {, abrótea }-1 \text {, cavala }-1 \text {, cherne }-1 \text {, perca }-1 \text {, raia }-1 \text {, solha }-1 \text {, } \\
\text { tamboril }-1 \text { ) }\end{array}$ & $\begin{array}{c}65 \\
(7,6 \%)\end{array}$ & $\begin{array}{c}33 \\
(8,0 \%)\end{array}$ & $\begin{array}{c}32 \\
(7,1 \%)\end{array}$ \\
\hline OVO & $\begin{array}{c}60 \\
(7,0 \%)\end{array}$ & $\begin{array}{c}50 \\
(12,2 \%)\end{array}$ & $\begin{array}{c}10 \\
(2,2 \%)\end{array}$ \\
\hline AMENDOIM & $\begin{array}{c}56 \\
(6,5 \%)\end{array}$ & $\begin{array}{c}32 \\
(7,8 \%)\end{array}$ & $\begin{array}{c}24 \\
(5,4 \%)\end{array}$ \\
\hline $\begin{array}{l}\text { SEMENTES } \\
(\text { sésamo }-13 \text {, girassol - 10, linhaça }-2 \text {, abóbora }-1)\end{array}$ & $\begin{array}{c}26 \\
(3,0 \%)\end{array}$ & $\begin{array}{l}7 \\
(1,7 \%)\end{array}$ & $\begin{array}{c}19 \\
(4,2 \%)\end{array}$ \\
\hline $\begin{array}{l}\text { CEREAIS } \\
\text { (trigo }-7 \text {, milho }-3 \text {, arroz }-2 \text {, cevada }-1 \text { ) }\end{array}$ & $\begin{array}{c}13 \\
(1,5 \%)\end{array}$ & $\begin{array}{c}9 \\
(2,2 \%)\end{array}$ & $\begin{array}{c}4 \\
(0,9 \%)\end{array}$ \\
\hline $\begin{array}{l}\text { CARNES } \\
\text { (carne aves }-4 \text {, carne porco }-3 \text {, carne vaca }-2 \text {, carne coelho }-2 \text { ) }\end{array}$ & $\begin{array}{c}10 \\
(1,2 \%)\end{array}$ & $\begin{array}{c}4 \\
(0,9 \%)\end{array}$ & $\begin{array}{c}6 \\
(1,3 \%)\end{array}$ \\
\hline 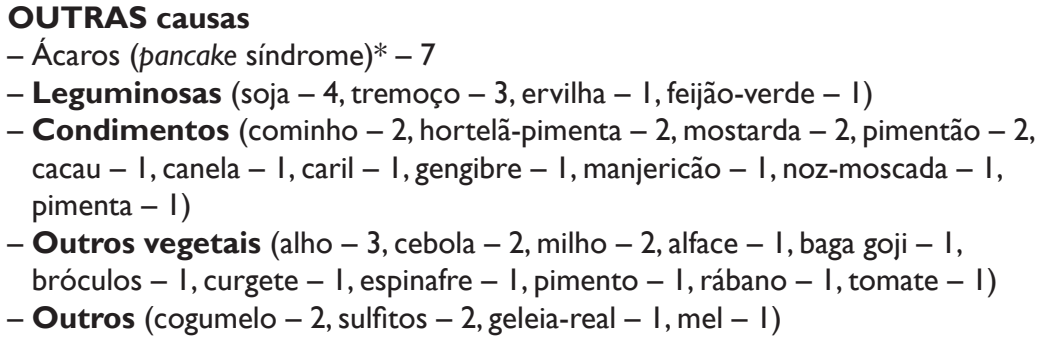 & $\begin{array}{c}52 \\
(6,1 \%)\end{array}$ & $\begin{array}{c}12 \\
(2,9 \%)\end{array}$ & $\begin{array}{c}40 \\
(8,9 \%)\end{array}$ \\
\hline
\end{tabular}

*anafilaxia induzida pela ingestão de farinha contaminada por ácaros 
Quadro 3. Causas de anafilaxia induzida por fármacos, e sua distribuição por grupo etário (n, \%), nas crianças e adolescentes com $<18$ anos e nos adultos com $\geq 18$ anos

\begin{tabular}{|c|c|c|c|}
\hline Etiologia da anafilaxia por fármacos & $\begin{array}{l}\text { Total de } \\
\text { doentes } \\
n=659(\%)\end{array}$ & $\begin{array}{l}<18 \text { anos } \\
n=57(\%)\end{array}$ & $\begin{array}{l}\geq 18 \text { anos } \\
n=602(\%)\end{array}$ \\
\hline AINE & $\begin{array}{c}285 \\
(43,3 \%)\end{array}$ & $25(43,9 \%)$ & $260(43,2 \%)$ \\
\hline $\begin{array}{l}\text { - Inibidores preferenciais da COX-I } \\
\text { (AAS - } 94 \text {, ibuprofeno }-8 \mathrm{I} \text {, diclofenac }-67 \text {, metamizol }-39 \text {, naproxeno }-4 \text {, } \\
\text { flurbiprofeno }-3 \text {, cetoprofeno }-2 \text {, cetorolac }-2 \text {, dexibuprofeno }-1 \text {, fentiazac }-2 \text {, } \\
\text { propifenazona }-2 \text {, aceclofenac }-1 \text {, etodolac }-1 \text { ) }\end{array}$ & 258 & 21 & 237 \\
\hline - Inibidores fracos da COX-I (paracetamol - I2) & 12 & 4 & 8 \\
\hline $\begin{array}{l}\text { - Inibidores preferenciais / selectivos da COX-2 } \\
\text { (nimesulide - I2, celecoxib - I, etoricoxib - I, parecoxib - I) }\end{array}$ & 15 & 0 & 15 \\
\hline ANTIBIÓTICOS & $\begin{array}{c}255 \\
(38,7 \%)\end{array}$ & $24(42,1 \%)$ & $163(37,1 \%)$ \\
\hline - Antibióticos beta-lactâmicos & 215 & 23 & 192 \\
\hline $\begin{array}{l}\text { - Penicilina / Derivados } \\
\text { (amoxicilina - 87, amoxicilina + AC - 37, penicilina - 24,AC - 7, flucloxacilina - 7, } \\
\text { ampicilina - 2) }\end{array}$ & 165 & 17 & 146 \\
\hline $\begin{array}{l}\text { - Cefalosporinas } \\
\text { (cefazolina }-27, \text { ceftriaxona }-8 \text {, cefuroxima }-6 \text {, cefoxitina }-3 \text {, cefradina }-2 \text {, } \\
\text { cefadroxil - I, cefalexina }-1 \text {, cefatrizina }- \text { I, ceftazidima }-1)\end{array}$ & 50 & 6 & 46 \\
\hline $\begin{array}{l}\text { - Antibióticos não beta-lactâmicos } \\
\text { - Quinolonas (ciprofloxacina - II, moxifloxacina - 5, levofloxacina - 3) } \\
\text { - Macrólidos (claritromicina - 5, espiramicina - I) } \\
\text { - Sulfonamidas (cotrimoxazol - 6) } \\
\text { - Outros (nitrofurantoína - 3, vancomicina - 2, isoniazida - I, fosfomicina - I, } \\
\text { gentamicina - I) }\end{array}$ & 40 & I & 39 \\
\hline ANESTÉSICOS & $40(6,1 \%)$ & 0 & $40(24,5 \%)$ \\
\hline $\begin{array}{l}\text { - Anestésicos gerais } \\
\text { - Relaxantes neuromusculares (atracúrio - 9, rocurónio - } 9 \text {, } \\
\text { cis-atracúrio - } 2 \text {, succinilcolina }-2 \text {, vecurónio - 2) } \\
\text { - Outros (midazolam }-5 \text {, propofol }-3 \text { ) }\end{array}$ & 33 & 0 & 33 \\
\hline - Anestésicos locais (lidocaína - 4, articaína - 2, bupivacaína - I, ropivacaína - I) & 7 & 0 & 7 \\
\hline $\begin{array}{l}\text { Citostáticos } \\
\text { (carboplatina }-7 \text {, oxaliplatina }-4 \text {, metotrexato }-2 \text {, docetaxel - I, paclitaxel - I, } \\
\text { tamoxifeno - I) }\end{array}$ & $16(2,4 \%)$ & 0 & $16(2,7 \%)$ \\
\hline $\begin{array}{l}\text { - IBP } \\
\text { (omeprazol - 8, esomeprazol - 3, pantoprazol - 3, lanzoprazol - I) }\end{array}$ & $14(2,1 \%)$ & 0 & $14(2,3 \%)$ \\
\hline $\begin{array}{l}\text { - Corticosteroides } \\
\text { (hidrocortisona - 7, metilprednisolona - 3, betametasona - I, deflazacort - I, } \\
\text { prednisolona - I) }\end{array}$ & $13(2,0 \%)$ & $2(3,5 \%)$ & II $(1,8 \%)$ \\
\hline
\end{tabular}


Ângela Gaspar, Natacha Santos, Emília Faria, Rita Câmara, Rodrigo Rodrigues-Alves, Isabel Carrapatoso, Eva Gomes, Ana Margarida Pereira, Leonor Carneiro-Leão, Mário Morais-Almeida, Luís Delgado, Elisa Pedro, Manuel Branco-Ferreira, Grupo de Interesse de "Anafilaxia e Doenças Imunoalérgicas Fatais" da SPAIC

\begin{tabular}{|c|c|c|c|}
\hline Etiologia da anafilaxia por fármacos (continuação) & $\begin{array}{c}\text { Total de } \\
\text { doentes } \\
n=659(\%)\end{array}$ & $\begin{array}{l}<18 \text { anos } \\
n=57(\%)\end{array}$ & $\begin{array}{l}\geq 18 \text { anos } \\
n=602(\%)\end{array}$ \\
\hline $\begin{array}{l}\text { - Analgésicos } \\
\text { (clonixina }-5, \text { tramadol }-2, \text { flupirtina }-1)\end{array}$ & $8(1,2 \%)$ & 0 & $8(1,3 \%)$ \\
\hline- MCR & $8(1,2 \%)$ & 0 & $8(1,3 \%)$ \\
\hline $\begin{array}{l}\text { - Outros } \\
\text { - Vitaminas (vitamina BI2 em } 3 \text { e vitamina D3 em I doente) } \\
\text { - Vacinas (vacina anti-tetânica em I adulto,VASPR e vacina anti- } \\
\text { meningocócica em I criança) } \\
\text { - Outros fármacos* }\end{array}$ & $29(4,4 \%)$ & $2(3,5 \%)$ & $27(4,5 \%)$ \\
\hline
\end{tabular}

AC - ácido clavulânico; AINE - anti-inflamatórios não esteróides; IBP - inibidores da bomba de protões; $\mathrm{MCl}$ - meios de contraste radiológico; VASPR - vacina contra sarampo, papeira e rubéola.

* Outros fármacos: atovaquona - I; atropina - 3; calcitonina - I; corante (azul patente) - 2; diosmina - I; hidroxizina - I; metoclopramida - 2; solução coloidal (Haemacell囚, Behring, Marburg, Alemanha) - I; ranitidina - 6; sulfassalazina -I; terbinafina - I; venlafaxina - I.

(AINE), os antibióticos e os agentes anestésicos. Outros fármacos implicados foram os citostáticos, os corticosteroides, os inibidores da bomba de protões e os meios de contraste radiológico, entre outros.

A causa mais frequente de anafilaxia induzida por fármacos, presente em 285 doentes (43\%), foi a AINE. Os AINE implicados encontram-se discriminados no Quadro 3, sendo referida a sua distribuição relativa no grupo etário pediátrico e adultos. Os AINE inibidores preferenciais da ciclo-oxigenase (COX)-I foram os principais implicados, com destaque para o AAS, o ibuprofeno, o diclofenac e o metamizol. Os AINE inibidores preferenciais da COX-2 foram implicados em 12 doentes, em todos os casos nimesulide, e os inibidores seletivos da COX-2 em três casos. Destaca-se o facto de em 12 doentes a anafilaxia ter sido induzida pelo paracetamol.

Duzentos e cinquenta e cinco doentes, dos quais 24 crianças, tinham anafilaxia induzida por antibióticos (39\%). Os antibióticos implicados encontram-se discriminados no Quadro 3, sendo referida a sua distribuição relativa no grupo etário pediátrico e nos adultos. $\mathrm{Na}$ maioria dos casos, correspondendo a 215 doentes, os antibióticos implicados foram os betalactâmicos, particularmente penicilinas e derivados, mas também cefalospo- rinas. Entre os antibióticos não betalactâmicos, todos em adultos, com exceção de uma criança com cotrimoxazol, as quinolonas foram os principais implicados, sendo a causa de anafilaxia em 19 doentes.

As penicilinas e derivados foram os principais antibióticos implicados, sendo a causa de anafilaxia em 165 doentes, com destaque para a amoxicilina, que foi a causa de anafilaxia induzida por antibiótico em $49 \%$ dos casos, comparativamente a $9 \%$ para a penicilina. As cefalosporinas foram a segunda causa de anafilaxia induzida por antibiótico (20\%), com destaque para a cefazolina, implicada em 27 doentes.

Os fármacos implicados nos 40 casos de anafilaxia induzida por agentes anestésicos foram todos reportados em adultos. Em 32 doentes foram implicados os anestésicos gerais, em contexto de anafilaxia intraoperatória, com destaque para os relaxantes neuromusculares (66\% dos casos), em 6 doentes o agente anestésico não foi identificado, em 7 os anestésicos locais foram os agentes implicados.

Em 132 doentes a causa da anafilaxia foi a picada de insetos. Os insetos reportados como agente causal da anafilaxia encontram-se discriminados no Quadro 4, sendo referida a sua distribuição relativa nos grupos etários com menos de 18 anos e com idade $\geq 18$ anos. Todos os 
Quadro 4. Anafilaxia induzida por picada de insetos e sua distribuição por grupo etário (n, \%), nas crianças e adolescentes com $<18$ anos e nos adultos com $\geq 18$ anos

\begin{tabular}{|l|c|c|c|}
\hline $\begin{array}{c}\text { Anafilaxia por } \\
\text { picada de insetos }\end{array}$ & $\begin{array}{c}\text { Total } \\
\text { de doentes } \\
\mathrm{n}=132(\%)\end{array}$ & $\begin{array}{c}<18 \text { anos } \\
\mathbf{n = 2 4}(\%)\end{array}$ & $\begin{array}{c}\geq 18 \text { anos } \\
\mathbf{n = 1 0 8}(\%)\end{array}$ \\
\hline \multicolumn{4}{|c|}{ Ordem: Hymenoptera } \\
\hline - Apis mellifera & $\begin{array}{c}93 \\
(70 \%)\end{array}$ & $\begin{array}{c}19 \\
(79 \%)\end{array}$ & $\begin{array}{c}74 \\
(69 \%)\end{array}$ \\
\hline - Vespula & $\begin{array}{c}30 \\
(23 \%)\end{array}$ & $\begin{array}{c}4 \\
(17 \%)\end{array}$ & $\begin{array}{c}26 \\
(24 \%)\end{array}$ \\
\hline - Polistes & $\begin{array}{c}12 \\
(9 \%)\end{array}$ & 0 & $\begin{array}{c}12 \\
(11 \%)\end{array}$ \\
\hline \multicolumn{5}{|c|}{ Ordem: Diptera } \\
\hline - Mosquito & $\begin{array}{c}\mathrm{I} \\
(\mathrm{I} \%)\end{array}$ & $\begin{array}{c}\mathrm{I} \\
(4 \%)\end{array}$ & 0 \\
\hline
\end{tabular}

casos foram associados a picada de himenópteros, com exceção de um rapaz de 7 anos, associado a picada de inseto não himenóptero. $\mathrm{A}$ idade média destes doentes foi de 39,5 \pm 18,5 anos, com uma idade mínima de 3 anos e idade máxima de 50 anos. A maioria (65\%) era do género masculino, que predominou em relação ao feminino (2:I). Apenas $13 \%$ tinham asma como comorbilidade.

A anafilaxia induzida pelo exercício foi reportada em 45 doentes. A idade média destes doentes foi de $26,4 \pm 13,2$ anos, com idades mínima de 5 anos e máxima de 65. A maioria era do género masculino (I,8:I). Em 44 doentes a anafilaxia foi reportada como sendo dependente de alimentos. Os alimentos implicados reportados foram: cereais (14, com destaque para trigo), frutos secos (10), frutas rosáceas (8, com destaque para maçã), amendoim (3), carne de aves (2), leite de vaca (2), leguminosas (2), uva (2), semente de sésamo (I) e outros vegetais (4). Apenas $20 \%$ tinham asma como comorbilidade.

A alergia ao látex foi causa de anafilaxia em 4 I doentes (Quadro 5), incluindo 6 crianças com malformações congénitas neurológicas/urológicas submetidas a intervenções cirúrgicas precoces na vida, em que a anafilaxia ocorreu maioritariamente após contacto com material contendo látex. Nos adultos, destaque para a síndrome látex-frutos como causa da anafilaxia. Os alimentos, frutos e outros vegetais responsáveis pelas reações de anafilaxia no contexto da síndrome látex-frutos encontram-se discriminados no Quadro 5. A castanha foi o alimento mais implicado (15 casos) nesta síndrome na população em causa. A idade média destes doentes foi de 36,8 8 15,2 anos, com idades mínima de 5 anos e máxima de 63. A maioria (88\%) era do género feminino, com relação feminino/masculino de 7. A maioria dos doentes (71\%) tinha asma. Destaque ainda para o facto de quase todos os casos de anafilaxia induzida pelo látex terem sido repor-

Quadro 5. Anafilaxia por alergia ao látex e sua distribuição por grupo etário (n, \%), nas crianças e adolescentes com $<18$ anos e nos adultos com $\geq 18$ anos

\begin{tabular}{|c|c|c|c|}
\hline Anafilaxia por alergia ao látex & $\begin{array}{l}\text { Total de doentes } \\
\quad n=41 \text { (\%) }\end{array}$ & $\begin{array}{l}<18 \text { anos } \\
n=6(\%)\end{array}$ & $\begin{array}{l}\geq 18 \text { anos } \\
n=35(\%)\end{array}$ \\
\hline - Anafilaxia por contacto com látex & $\begin{array}{c}29 \\
(70 \%)\end{array}$ & $\begin{array}{c}5 \\
(83 \%)\end{array}$ & $\begin{array}{c}24 \\
(69 \%)\end{array}$ \\
\hline - Anafilaxia intraoperatória & 5 & 0 & 5 \\
\hline $\begin{array}{l}\text { - Anafilaxia por contacto com material contendo látex } \\
\text { (luvas }-17 \text {, balão }-4 \text {, cateter }-1 \text {, preservativo }-I \text {, brinquedo }-1 \text { ) }\end{array}$ & 24 & 5 & 19 \\
\hline $\begin{array}{l}\text { - Síndrome látex-frutos } \\
\text { (castanha }-15 \text {, banana }-7 \text {, maracujá }-6 \text {, kiwi }-3 \text {, pêssego }-3 \text {, abacate - } \\
2 \text {, espinafre }-2 \text {, figo }-2 \text {, mandioca }-2 \text {, manga }-2 \text {, melão }-2 \text {, tomate }-2 \text {, } \\
\text { ananás - I, batata doce }-1 \text {, papaia }-1 \text {, pimentão-doce }-1 \text { ) }\end{array}$ & $\begin{array}{c}21 \\
(51 \%)\end{array}$ & $\begin{array}{l}1 \\
(17 \%)\end{array}$ & $\begin{array}{c}20 \\
(57 \%)\end{array}$ \\
\hline
\end{tabular}


Ângela Gaspar, Natacha Santos, Emília Faria, Rita Câmara, Rodrigo Rodrigues-Alves, Isabel Carrapatoso, Eva Gomes, Ana Margarida Pereira, Leonor Carneiro-Leão, Mário Morais-Almeida, Luís Delgado, Elisa Pedro, Manuel Branco-Ferreira, Grupo de Interesse de "Anafilaxia e Doenças Imunoalérgicas Fatais" da SPAIC

tados durante os primeiros cinco anos do estudo, tendo sido apenas um caso reportado nos últimos cinco anos, traduzindo uma tendência para redução da exposição e alergia ao látex.

Quarenta doentes apresentavam anafilaxia induzida pelo frio (Quadro I). A idade média destes doentes foi de $22,7 \pm 16,9$ anos, mínima de 2 e máxima de 66 . A maioria $(63 \%)$ era do género feminino, com uma relação feminino/masculino de I,6. Tinham asma como comorbilidade em $28 \%$ dos casos.

\section{DISCUSSÃo}

Este estudo confirma a alergia alimentar como a causa mais frequente de anafilaxia em Portugal, sendo em idade pediátrica responsável por mais de três quartos dos casos. Outras etiologias identificadas foram os fármacos, principal causa em idade adulta, particularmente AINE e antibióticos betalactâmicos, a picada de insetos, o exercício (na quase totalidade AIEDA), o látex (anafilaxia induzida pelo contacto com látex ou em contexto de síndrome látex-frutos) e a anafilaxia induzida pelo frio.

A uniformização prévia dos critérios de diagnóstico de anafilaxia e a realização das notificações por médicos com diferenciação em Imunoalergologia permitiu a aplicação de uma metodologia sobreponível e validada a nível nacional em que a qualidade dos dados apresentados é uma importante mais-valia, compensando a esperada sub-notificação de casos inerente à notificação por participação voluntária.

Os resultados deste estudo permitem verificar que a ocorrência de anafilaxia é transversal a todos os grupos etários. À semelhança do observado por outros autores, encontramos um predomínio de anafilaxia reportada em adultos e no género feminino, enquanto nas crianças predominou o género masculino $0^{5, I 1,15}$. Tem sido sugerido que fatores endócrinos, especialmente em mulheres em idade fértil, possam estar envolvidos na patogénese, tal como ocorre noutras doenças de base imunológica ${ }^{5,15}$.
Os alergénios alimentares constituíram a etiologia mais frequente, como tem sido descrito em várias séries, especialmente quando são incluídas crianças na avaliação ${ }^{11,12,13,16}$. O leite de vaca e os crustáceos foram a principal causa nesta população, respetivamente em crianças e em adultos, divergindo de achados obtidos por outros autores $^{16,17,18}$, o que realça a importância do conhecimento detalhado da realidade de cada país. Outros alimentos implicados foram as frutas frescas, os frutos secos, 0 peixe, o ovo, o amendoim e as sementes, entre outros.

Esta situação tem importantes repercussões sociais e de qualidade de vida, sendo que o contacto com o alergénio alimentar, mesmo em quantidades mínimas, pode ser perturbador e grave. A ingestão não reconhecida do alergénio oculto noutros alimentos pode colocar a vida do doente alérgico em risco. Reforça-se a importância da rotulagem, sendo que acidentes relacionados com a exposição a alergénios ocultos continuam a acontecer, e o desfecho pode ser fatal.

Relativamente às causas de anafilaxia em idade pediátrica, os resultados são coincidentes com estudos anteriores realizados em Portugal|1,12,13. Nestes estudos, as principais causas de anafilaxia foram os alimentos em 71 a $84 \%$, os fármacos em 8 a $11 \%$ e a picada de insetos em 2 a $6 \%$. No levantamento dos casos de anafilaxia efetuado pela Sociedade Latino-Americana de Asma, Alergia e Imunologia (SLAAI), pela aplicação do inquérito OLASA (Online Latin American Survey of Anaphylaxis) em idade pediátrica, os alimentos foram igualmente a causa mais frequente, com incremento da alergia a fármacos $(28 \%)$ e a picada de insetos $(26 \%)^{19}$.

De entre os alimentos, o leite de vaca é o mais frequentemente implicado como causa de anafilaxia em idade pediátrica, como reportado em estudos anteriores (4I a $53 \%)^{11,12,13,20}$, sendo mais frequente nos primeiros anos de vida ${ }^{12,16,21}$. Segundo Silva et al. ${ }^{13}$, o leite foi o alimento causal em $47 \%$ das crianças com anafilaxia alimentar, seguido de peixe, crustáceos e moluscos (23\%), frutos secos (14\%) e ovo (9\%). Segundo Gaspar et al. ${ }^{12}$, os alimentos implicados foram o leite em $41 \%$ das crian- 
ças, ovo em 13\%, frutos frescos, frutos secos e amendoim em $11 \%$ e peixe e crustáceos em $7 \%$. No presente estudo, observa-se um aumento da frequência de anafilaxia a frutos secos em idade pediátrica para os $16 \%$.

A anafilaxia induzida por frutos secos tem sido cada vez mais frequentemente reportada a nível mundial e particularmente em idade pré-escolar ${ }^{16,17,20}$. Na presente série, os frutos secos são uma causa importante de anafilaxia alimentar (I5\%), sendo em idade pediátrica a segunda causa de anafilaxia alimentar, após o leite de vaca. $\mathrm{Na}$ presente amostra, a noz e o caju foram os frutos secos mais frequentemente implicados. Estes são também os principais alergénios relacionados com a alergia a frutos secos nos Estados Unidos, sendo a avelã a causa principal na Europa ${ }^{18}$. Num estudo recente no nosso país, na região de Coimbra os frutos secos foram a principal causa de anafilaxia alimentar (19\%), sendo a noz e a avelã os principais frutos secos implicados ${ }^{22}$. A frequência observada tem variações, de acordo com o grupo etário estudado e a região geográfica e os hábitos alimentares associados.

As LTP são panalergénios resistentes ao calor e à hidrólise gástrica presentes em diversas espécies vegetais, como frutos frescos, leguminosas, frutos secos e sementes. Constituem uma causa comum de anafilaxia induzida por alimentos na Europa mediterrânica ${ }^{23,24}$ e têm sido apontadas como a principal causa de AIEDA ${ }^{23,24}$. A gestão do plano alimentar nestes doentes é desafiante pela presença destes alergénios num grande número de vegetais.

Mota et al. ${ }^{24}$, na região de Lisboa, identificaram as LTP como causa importante de anafilaxia alimentar (17\% dos casos), a terceira causa de anafilaxia induzida por alimentos, após o marisco (20\%) e o leite de vaca (19\%), seguida pelos frutos secos, ovo, amendoim e peixe. Em estudos realizados em Itália ${ }^{23}$ e Espanha ${ }^{25}$, as LTP foram a principal causa de anafilaxia alimentar em adultos, com destaque para o pêssego. No presente estudo, o realce vai também para o pêssego.

$\mathrm{Na}$ abordagem específica da AIEDA é imprescindível a evicção dos alimentos implicados nas 4 a 6 horas antes da prática desportiva, e a realização do exercício físico deve ser sempre acompanhado por parceiro capaz de administrar o dispositivo autoinjetor de adrenalina.

A primeira etiologia mais frequente em adultos e a segunda em crianças foi a anafilaxia a fármacos, predominando os AINE sobre os antibióticos. Nesta série observou-se uma baixa percentagem de anafilaxia a fármacos em crianças e adolescentes (II\%). A menor prevalência de reações de hipersensibilidade a fármacos observada em idade pediátrica, comparativamente ao adulto, é explicada pela menor exposição e por mecanismos de resposta imunológica distintos dos do adulto ${ }^{10}$.

Os AINE foram a principal causa de anafilaxia a fármacos, à semelhança do encontrado em outras séries em doentes não hospitalizados ${ }^{26,27}$; no entanto, em vários estudos os antibióticos são a primeira etiologia de anafilaxia induzida por fármacos ${ }^{28,29}$, estimando-se um risco elevado de anafilaxia à penicilina na população geral nos Estados Unidos entre 0,7 e $10 \%{ }^{29}$. Nas crianças, o número de casos de anafilaxia a antibióticos foi semelhante ao dos AINE.

Entre os AINE os principais implicados foram os inibidores preferenciais da COX-I, com destaque para - AAS, o ibuprofeno, o diclofenac e o metamizol, à semelhança do encontrado em outras séries ${ }^{10,26,27}$, que constituíram a maioria dos casos reportados. Foram raras as reações anafiláticas descritas aos AINE preferenciais da COX-2 (4\%), ao paracetamol (4\%) e aos AINE inibidores seletivos da COX-2 (3 casos reportados), sendo considerados fármacos alternativos nos casos de anafilaxia aos AINE inibidores preferenciais da COX-| $10,26,27$.

À semelhança do descrito em outras séries, a anafilaxia atribuída aos antibióticos da classe dos betalactâmi$\cos (84 \%)$ foi mais elevada do que aos não betalactâmicos 10,27,29,30. Encontrou-se maior frequência de anafilaxia à amoxicilina e às cefalosporinas, em detrimento das benzilpenicilinas, à semelhança do observado em outras séries $^{10,27,31}$, o que pode ser explicado por alterações no padrão de prescrição aos betalactâmicos na Europa. Destaca-se a anafilaxia à cefazolina, implicada em $54 \%$ dos 
Ângela Gaspar, Natacha Santos, Emília Faria, Rita Câmara, Rodrigo Rodrigues-Alves, Isabel Carrapatoso, Eva Gomes, Ana Margarida Pereira, Leonor Carneiro-Leão, Mário Morais-Almeida, Luís Delgado, Elisa Pedro, Manuel Branco-Ferreira, Grupo de Interesse de "Anafilaxia e Doenças Imunoalérgicas Fatais" da SPAIC

doentes alérgicos às cefalosporinas, e particularmente em casos de anafilaxia intraoperatória.

Outros fármacos implicados foram, por ordem decrescente, os anestésicos (com destaque para os relaxantes neuromusculares), os citostáticos, os corticosteroides, os inibidores da bomba de protões e os meios de contraste radiológico, entre outros. As reações graves atribuídas aos meios de contraste têm vindo a diminuir devido ao facto de atualmente já não serem usadas formulações iónicas de elevada osmolalidade. Em estudos realizados na população geral nos Estados Unidos estima-se uma prevalência de anafilaxia a meios de contraste radiológico entre 0,22 e $1 \%^{29}$, próximo do obtido nesta população $(1,2 \%)$.

Os acidentes alérgicos relacionados com a toma de medicamentos devem ser notificados e bem conhecidos pelo próprio e seus prestadores de cuidados. Alternativas podem ser testadas e, em alguns casos, o especialista em Imunoalergologia pode conduzir protocolos de dessensibilização específica, se indicados.

Vários estudos sugerem que o diagnóstico de asma é um fator de risco para a ocorrência de reações anafiláticas mais graves, potencialmente fatais ${ }^{1,4,5}$. Uma das limitações deste estudo foi o facto de não se terem categorizado as reações segundo o grau de gravidade. No entanto, observamos que os doentes com asma não tiveram maior frequência de sintomas mais graves, como edema da glote, sintomas cardiovasculares ou perda de consciência, bem como não houve diferenças no recurso a serviço de urgência ou a administração de adrenalina.

Em relação aos sintomas gastrintestinais, Rudders et al. 32 descrevem que, apesar de presentes de forma uniforme em todos os grupos etários, são mais frequentes em crianças, e particularmente em idade pré-escolar. No presente estudo, $51 \%$ das manifestações gastrintestinais ocorreram em crianças em idade pré-escolar, pelo que se reforça a importância da inclusão destes sintomas nos critérios de diagnóstico de Sampson et al. ${ }^{3}$, sobretudo em idades mais jovens. Por outro lado, a inexistência de sintomas cutâneos, como aconteceu em $4 \%$ dos doentes reportados, não exclui o diagnóstico de anafilaxia.

$\mathrm{Em} 80 \%$ dos casos os doentes receberam assistência em serviço de urgência, sendo que $20 \%$ justificaram internamento hospitalar. A anafilaxia é uma emergência médica que requer tratamento imediato, sendo a adrenalina $\circ$ tratamento de primeira linha segundo os consensos de anafilaxia ${ }^{1}, 4,16,30$, estando comprovada a associação com o aumento de mortalidade de anafilaxia refratária e de anafilaxia bifásica na ausência ou no atraso da administração de adrenalina ${ }^{1,4,30}$. A administração de adrenalina por via intramuscular na face antero-lateral da coxa, na dose de $0,01 \mathrm{mg} / \mathrm{kg}$ (máximo de $0,5 \mathrm{mg}$ ), é o tratamento de primeira linha da reação anafilática ${ }^{1,16,33}$. No entanto, apesar de recomendada por todos os consensos, a adrenalina continua a ser subutilizada em serviço de urgência. Observamos que menos de metade dos doentes receberam tratamento com adrenalina, próximo do referido por outras séries ${ }^{19,34}$ mas inferior ao reportado por outros autores ${ }^{20,21}$, pelo que se enfatiza a importância de continuar o trabalho iniciado na formação médica pré e pós-graduada e a necessidade de implementar e divulgar nos serviços de urgência os protocolos corretos de abordagem da anafilaxia.

A prescrição do dispositivo autoinjetor de adrenalina também ficou aquém do desejável. É conhecida a subprescrição de adrenalina pelos clínicos nos casos de anafilaxia, também uma realidade em Portugal, como foi previamente demonstrado em estudo realizado por Branco-Ferreira et al. ${ }^{35}$. O dispositivo autoinjetor de adrenalina deve ser prescrito nos casos de anafilaxia, pelo risco de recorrências, podendo também transmitir segurança e minimizar o receio com a ingestão posterior de alimentos, ou a administração posterior de fármacos, frequentemente observado nestes doentes em consequência da sensação de morte iminente eventualmente sofrida.

As recorrências aconteceram em quase metade dos doentes (4I\%), sendo que em $21 \%$ ocorreram três ou mais episódios de anafilaxia. É de referir que $7 \%$ dos doentes já utilizaram com sucesso o dispositivo autoin- 
jetor de adrenalina. Durante o período do estudo não foi reportado nenhum caso fatal.

Sendo conhecida a subutilização dos dispositivos autoinjetores de adrenalina pelos doentes/prestadores de cuidados a quem foram prescritos, para além da informação verbal deve ser entregue informação escrita e reforçado o ensino em cada reavaliação, nomeadamente através do recurso a dispositivos de placebo, reproduzindo uma situação tão real quanto possível, insistindo na eficácia e segurança do procedimento.

No caso da anafilaxia a fármacos, e uma vez identificado o risco, poderá, em casos pontuais, ser discutível a prescrição de adrenalina para o domicílio, nomeadamente nos casos de anafilaxia a agentes de diagnóstico ou terapêutica de utilização exclusivamente intra-hospitalar.

No presente estudo, num período de dez anos, a ocorrência de anafilaxia no decurso da realização de imunoterapia específica foi um evento raramente reportado, tendo sido notificados apenas quatro casos, três doentes durante imunoterapia por via subcutânea a aeroalergénios (dois com extrato alergénico de ácaros e um com extrato alergénico de pólenes) e um doente durante imunoterapia a veneno de abelha em esquema de manutenção.

Salienta-se ainda o facto de, neste estudo, ter sido possível concluir a causa da anafilaxia na quase totalidade dos doentes reportados. A anafilaxia idiopática pode ser responsável até $20 \%$ de todos os casos de anafilaxia 1,30; no entanto, este diagnóstico de exclusão representou na presente série uma raridade ( $2 \%)$, confirmando que o estudo etiológico da anafilaxia deve ser sempre detalhado e reforçando a importância da referência de todos os casos para consultas de Imunoalergologia.

Por a anafilaxia ser o protótipo de uma reação adversa imprevisível e potencialmente fatal, a prevenção é fundamental. É crucial a educação dos doentes/prestadores de cuidados para a correta valorização dos ingredientes descritos nos rótulos, sobretudo em situações de alergia alimentar com potencial de reações graves, mesmo quando em quantidades vestigiais, particularmente para o leite, os frutos secos, o amendoim e o ovo. A todos os doentes/prestadores de cuidados deve ser entregue um documento contendo os agentes a evitar e eventuais alternativas, bem como o tratamento a realizar em caso de contacto acidental. $O$ reconhecimento dos sinais de anafilaxia e a precoce e correta utilização do dispositivo autoinjetor de adrenalina devem ser reforçados em cada consulta. A administração precoce de adrenalina no início do quadro clínico é de extrema importância e a necessidade de referenciação urgente para consulta de Imunoalergologia para o correto diagnóstico após o primeiro episódio é salientada pela grande frequência de recidivas, realçando o papel imprescindível do Imunoalergologista na abordagem da anafilaxia.

\section{CONCLUSÕES}

Ao longo de 10 anos, este projeto de âmbito nacional da SPAIC permitiu uma extensa caracterização detalhada (feita por médicos com diferenciação em Imunoalergologia) de doentes com clínica de anafilaxia, em que as causas mais frequentemente identificadas foram os alimentos, os fármacos e os venenos de himenópteros.

Realçamos a distribuição etária incluindo um amplo espetro, a diferente distribuição por género em idade pediátrica e adultos, a importância dos alergénios alimentares em ambos os grupos etários e dos fármacos em idade adulta, a frequente associação a outras comorbilidades, como asma, bem como a elevada probabilidade da recorrência das manifestações clínicas e a limitada percentagem de casos em que a adrenalina foi utilizada como terapêutica de emergência.

Reforça-se a importância de uma adequada e agilizada rede de referenciação em Imunoalergologia, de forma a melhorar o diagnóstico correto, a adotar medidas efetivas de prevenção, como a evicção alergénica, a estruturar a atuação em caso de emergência, a oferecer alternativas (alimentares, medicamentosas) e a implementar o tratamento, com imunoterapia específica (himenópteros, lá- 
Ângela Gaspar, Natacha Santos, Emília Faria, Rita Câmara, Rodrigo Rodrigues-Alves, Isabel Carrapatoso, Eva Gomes, Ana Margarida Pereira, Leonor Carneiro-Leão, Mário Morais-Almeida, Luís Delgado, Elisa Pedro, Manuel Branco-Ferreira, Grupo de Interesse de "Anafilaxia e Doenças Imunoalérgicas Fatais" da SPAIC

tex, alimentos) ou dessensibilização específica/indução de tolerância (alimentos, medicamentos).

O verdadeiro impacto epidemiológico da anafilaxia a nível nacional necessita, no entanto, ainda de ser aprimorado. A nova rede de base de dados promovida pela SPAIC, e a sua notificação e registo em base única (Registo $\mathrm{Na}$ cional de Anafilaxia, ReNA), assim como o Catálogo de Alergias e outras Reações Adversas (CPARA) implementado em Portugal fazem vislumbrar o caminho para meIhorar o conhecimento e delinear melhores estratégias de prevenção e tratamento da anafilaxia com âmbito nacional.

\section{Agradecimentos}

Aos Drs. Alberto Costa, Alexandra Santos, Amélia Spínola Santos, Ana Célia Costa, Ana Margarida Reis, Ana Mendes, Ana Moreira, Ana Morête, Ana Romeira, Ana Teresa Silva, Anabela Lopes, António Jorge Cabral, Carla Loureiro, Carlos Lozoya, Carlos Neto Braga, Carlos Nunes, Carmen Botelho, Cristina Arêde, Cristina Santa Marta, Daniela Malheiro, Eugénia Almeida, Eunice Castro, Fátima Duarte, Filipa Sousa, Filipe Benito Garcia, Francisca Carvalho, Graça Pires, Graça Sampaio, Helena Falcão, Helena Pité, Inês Mota, Isabel Mascarenhas, Joana Caiado, João Antunes, João Gaspar Marques, José Geraldo Dias, José Luís Plácido, Josefina Rodrigues Cernadas, Leonor Viegas, Luís Araújo, Luís Miguel Borrego, Luísa Geraldes, Magna Alves Correia, Margarida Cortez Castro, Mariana Couto, Marta Chambel, Marta Neto, Miguel Paiva, Natália Páris Fernandes, Nuno Sousa, Paula Leiria Pinto, Pedro Lopes da Mata, Pedro Martins, Rosa Anita Fernandes, Rui Silva, Sara Pereira da Silva, Sara Prates, Sofia Campina, Sónia Rosa, Susana Cadinha, Susana Carvalho, Susana Lopes da Silva, Susana Oliveira, Susana Palma Carlos, Susana Piedade, Susel Ladeira, Teresa AImeida Vau, Teresa Conde, Teresa Moscoso, pela contribuição na notificação de casos de anafilaxia.

\section{Conflito de interesses}

Os autores declaram que não existem conflitos de interesse.
Contacto:

Ângela Gaspar

Serviço de Imunoalergologia, Hospital da Luz

Av. Lusíada 100

1500-650 Lisboa

E-mail: angela.gaspar@sapo.pt

\section{REFERÊNCIAS}

I. Simons FE, Ardusso LR, Bilo MB, El-Gamal YM, Ledford DK, Ring J, et al. World Allergy Organization guidelines for the assessment and management of anaphylaxis. J Allergy Clin Immunol 201I; 127:587-93.el-22.

2. Johansson SG, Bieber T, Dahl R, Friedmann PS, Lanier BQ, Lockey RF, et al. Revised nomenclature for allergy for global use: Report of the nomenclature review committee of the World Allergy Organization, October 2003. J Allergy Clin Immunol 2004; II3:832-6.

3. Sampson HA, Muñoz-Furlong A, Campbell RL, Adkinson NFJr, Bock $S A, B r a n u m ~ A$, et al. Second symposium on the definition and management of anaphylaxis: summary report-Second National Institute of Allergy and Infectious Disease/Food Allergy and Anaphylaxis Network symposium. J Allergy Clin Immunol 2006;117:391-7.

4. Muraro A, Roberts G, Clark A, Eigenmann PA, Halken S, Lack $\mathrm{G}$, et al. The management of anaphylaxis in childhood: position paper of the European academy of allergology and clinical immunology. Allergy 2007;62:857-71.

5. Lieberman P, Camargo CA Jr, Bohlke K, Jick H, Miller RL, Sheikh A, Simons FE. Epidemiology of anaphylaxis: findings of the American College of Allergy, Asthma and Immunology Epidemiology of Anaphylaxis Working Group. Ann Allergy Asthma Immunol 2006;97:596-602.

6. Panesar SS, Javad S, de Silva D, Nwaru BI, Hickstein L, Muraro A, et al; EAACI Food Allergy and Anaphylaxis Group. The epidemiology of anaphylaxis in Europe: A systematic review. Allergy 2013;68:1353-61.

7. Peng MM, Jick H. A population-based study of the incidence, cause, and severity of anaphylaxis in the United Kingdom. Arch Intern Med 2004;164:317-9.

8. Tang ML, Osborne N, Allen K. Epidemiology of anaphylaxis. Curr Opin Allergy Clin Immunol 2009;9:35I-6.

9. Liew WK, Williamson E, Tang ML. Anaphylaxis fatalities and admissions in Australia. J Allergy Clin Immunology 2009;123:434-42.

10. Faria E, Rodrigues-Cernadas J, Gaspar A, Botelho C, Castro E, Lopes A, et al; Portuguese Society of Allergology and Clinical Immunology; Drug Allergy Interest Group. Drug-Induced Anaphylaxis Survey in Portuguese Allergy Departments. J Investig Allergol Clin Immunol 2014;24:40-8. 
II. Morais-Almeida M, Gaspar A, Santa-Marta C, Piedade S, Leiria-Pinto P, Pires G, et al. Anafilaxia - Da notificação e reconhecimento à abordagem terapêutica. Rev Port Imunoalergologia 2007;15:19-4|.

12. Gaspar A, Santos N, Piedade S, Santa-Marta C, Pires G, Sampaio $\mathrm{G}$, et al. One-year survey of paediatric anaphylaxis in an allergy department. Eur Ann Allergy Clin Immunol 2015;47:197-205.

13. Silva R, Gomes E, Cunha L, Falcao H. Anaphylaxis in children: a nine years retrospective study (200I-2009). Allergol Immunopathol (Madr) 2012;40:31-6.

14. Botelho C, Cruz L, Rodrigues J, Castel-Branco MG. Anafilaxia: Revisão de 10 anos num hospital central de Portugal. Rev Port Imunoalergologia 2008;16:57-7I.

15. Sheikh A, Alves B. Age, sex, geographical and socio-economic variations in admissions for anaphylaxis: analysis of four years of English hospital data. Clin Exp Allergy 2001;31:1571-6.

16. Muraro A, Werfel T, Hoffmann-Sommergruber K, Roberts G, Beyer K, Bindslev-Jensen C, et al. EAACl food allergy and anaphylaxis guidelines: diagnosis and management of food allergy. Allergy 2014;69:1008-25.

17. Johnson J, Malinovschi A, Alving K, Lidholm J, Borres MP, Nordvall $L$. Ten-year review reveals changing trends and severity of allergic reactions to nuts and other foods. Acta Paediatr 2014;103:862-7.

18. Weinberger T, Sicherer S. Current perspectives on tree nut allergy: a review. J Asthma Allergy 20I8;II:4I-5I.

19. Solé D, Ivancevich JC, Borges MS, Coelho MA, Rosário NA, Ardusso L, et al; Latin American Anaphylaxis Working Group. Anaphylaxis in Latin American children and adolescents: the Online Latin American Survey on Anaphylaxis (OLASA). Allergol Immunopathol (Madr) 2012;40:33I-5.

20. de Silva IL, Mehr SS, Tey D, Tang ML. Paediatric anaphylaxis: a 5 year retrospective review. Allergy 2008;63:107I-6.

21. Hoffer V, Scheuerman O, Marcus N, Levy Y, Segal N, Lagovsky I, et al. Anaphylaxis in Israel: experience with 92 hospitalized children. Pediatr Allergy Immunol 2011;22:172-7.

22. Fernandes RA, Regateiro F, Pereira C, Faria E, Pita J, Todo-Bom $A$, et al. Anaphylaxis in a food allergy outpatient department: one-year review. Eur Ann Allergy Clin Immunol 2018;50:8I-8.

23. Asero R, Antonicelli L, Arena A, Bommarito L, Caruso B, ColomboG, et al. Causes of food-induced anaphylaxis in Italian adults: a multi-centre study. Int Arch Allergy Immunol 2009;150:27I-7.
24. Mota I, Gaspar A, Benito-Garcia F, Correia M, Arêde C, Piedade $S$, et al. Anaphylaxis caused by lipid transfer proteins: an unpredictable clinical syndrome. Allergol Immunopathol (Madr). 2018;46:565-70.

25. Pascal M, Munoz-Cano R, Reina Z, Palacin A, Vilella R, Picado C, et al. Lipid transfer protein syndrome: clinical pattern, cofactor effect and profile of molecular sensitization to plant-foods and pollens. Clin Exp Allergy 2012;42:1529-39.

26. Kowalski ML, Makowska JS, Blanca M, Bavbek S, Bochenek G, Bousquet J, et al. Hypersensitivity to nonsteroidal anti-inflammatory drugs (NSAIDs) - classification, diagnosis and management: review of the EAACI/ENDA and GA2LEN/HANNA. Allergy 2011;66:818-29.

27. Mota I, Gaspar A, Benito-Garcia F, Correia M, Chambel M, Morais-Almeida $M$. Drug-induced anaphylaxis: seven-year single-center survey. Eur Ann Allergy Clin Immunol 2018;50:2II-6.

28. Cianferoni A, Novembre E, Mugnaini L, Lombardi E, Bernardini $\mathrm{R}$, Pucci N, et al. Clinical features of acute anaphylaxis in patients admitted to a university hospital: an II-year retrospective review (1985-1996). Ann Allergy Asthma Immunol 2001;87:27-32.

29. Neugut Al, Ghatak AT, Miller RL. Anaphylaxis in the United States: an investigation into its epidemiology. Arch Intern Med 2001;161:1521.

30. Lieberman P, Nicklas RA, Oppenheimer J, Kemp SF, Lang DM, Bernstein DI, et al. The diagnosis and management of anaphylaxis practice parameter: 2010 update. J Allergy Clin Immunol 2010;126:477-80.el-42.

31. Blanca Gomez M, Torres MJ, Mayorga C, Perez-Inestrosa E, Suau $\mathrm{R}$, Montañez $\mathrm{MI}$, et al. Immediate allergic reactions to betalactams: facts and controversies. Curr Opin Allergy Clin Immunol 2004; 4:26I-6.

32. Rudders SA, Banerji A, Clark S, Camargo CA Jr. Age-related differences in the clinical presentation of food-induced anaphylaxis. J Pediatr 20II;158:326-8.

33. Carneiro-Leão L, Santos N, Gaspar A. Anaphylaxis, Diagnosis and Treatment. Acta Med Port 2018; 31:134-5.

34. Prince BT, Mikhail I, Stukus DR. Underuse of epinephrine for the treatment of anaphylaxis: missed opportunities. J Asthma Allergy 2018; II:|43-5I.

35. Ferreira MB, Alves RR. Are general practitioners alert to anaphylaxis diagnosis and treatment? Eur Ann Allergy Clin Immunol 2006;38:83-6. 
Ângela Gaspar, Natacha Santos, Emília Faria, Rita Câmara, Rodrigo Rodrigues-Alves, Isabel Carrapatoso, Eva Gomes, Ana Margarida Pereira, Leonor Carneiro-Leão, Mário Morais-Almeida, Luís Delgado, Elisa Pedro, Manuel Branco-Ferreira, Grupo de Interesse de "Anafilaxia e Doenças Imunoalérgicas Fatais" da SPAIC

Anexo I. Critérios clínicos para o diagnóstico de anafilaxia (Adaptado de Sampson et al. ${ }^{3}$ )

Considera-se anafilaxia quando exista uma reação sistémica grave na presença de pelo menos um dos três critérios clínicos seguintes:

Início súbito (minutos a poucas horas) com envolvimento da pele elou mucosas (ex.: urticária, eritema ou prurido generalizado, edema dos lábios, da língua ou da úvula) e pelo menos um dos seguintes:

a. Compromisso respiratório (ex.: dispneia, sibilância/broncospasmo, estridor, diminuição do FEV / PEF, hipoxemia);

b. Hipotensão ou sintomas associados de disfunção de órgão terminal (ex.: hipotonia, colapso, síncope, incontinência de esfíncteres).

Ocorrência de dois ou mais dos seguintes rapidamente após exposição a um alergénio provável para aquele doente (minutos a poucas horas):

a. Envolvimento da pele e/ou mucosas (ex.: urticária, eritema ou prurido generalizado, edema dos lábios, da língua ou da úvula);

b. Compromisso respiratório (ex.: dispneia, sibilância/broncospasmo, estridor, diminuição do FEV / PEF, hipoxemia);

c. Hipotensão ou sintomas associados de disfunção de órgão terminal (ex.: hipotonia, colapso, síncope, incontinência de esfíncteres);

d. Sintomas gastrintestinais persistentes (ex.: dor abdominal em cólica, vómitos).

Hipotensão após exposição a um alergénio conhecido para aquele doente (minutos a poucas horas):

a. Lactentes e crianças: PA sistólica reduzida (específica para a idade) ou diminuição da PA sistólica superior a 30\%*;

b.Adultos: PA sistólica inferior a $90 \mathrm{mmHg}$ ou diminuição do valor basal do doente superior a $30 \%$.

$\mathrm{FEV}_{\text {I }}$ - Volume expiratório forçado no primeiro segundo; PEF - Débito expiratório máximo instantâneo; PA - Pressão arterial

* PA sistólica diminuída para crianças é definida como inferior a $70 \mathrm{mmHg}$ entre as idades de I mês a I ano; menos de $70 \mathrm{mmHg}$

+ de 2 x idade de I aos 10 anos; inferior a $90 \mathrm{mmHg}$ dos $1 \mathrm{I}$ aos 17 anos 
Anexo 2. Questionário do sistema de notificação de anafilaxia de âmbito nacional da SPAIC implementado em 2007 e disponibilizado a todos os médicos com diferenciação em Imunoalergologia e sócios da SPAIC

\section{Sistema de Notificação de Anafilaxia (ver anexo)}

\section{Identificação do Paciente}

Nome: (iniciais)

Nascimento: (mês/ano)

Sexo

$\square$ Feminino

Residência: (concelho)

\section{Causa relaccionada com a Anafilaxia}

Alergia Alimentar $\rightarrow$ Indique o(s) Alimento(s):

Alergia Medicamentosa $\rightarrow$ Indique o(s) Fármaco(s):

$\square$ Alergia Veneno Himenópteros $\rightarrow$ Indique o(s) Insecto(s):

$\square$ Alergia ao Látex $\rightarrow$ Síndrome Látex-Frutos: $\square$ Sim $\square$ Não

$\square$ Induzida pelo Exercício $\rightarrow$ Dependente de Alimentos: $\square$ Sim $\quad \square$ Não Indique o(s) Alimento(s):

Induzida pelo Frio / Outros Agentes Físicos

Idiopática Outra causa

Descrição da Reacção:

Data em que ocorreu a Anafilaxia: / I (dia/mês/ano) Se desconhecida, indique a idade do doente na data da reacção: (anos) No de episódios de Anafilaxia:

(se vários episódios, coloque a data da 1 a reacção anafiláctica)

\section{Tratamento}

$\square$ Adrenalina

Recurso ao SU

Outro:

$\square$ Internamento Hospitalar $\quad \square$ Desfecho Fatal

Prescrição de Kit de Adrenalina $\square$ Necessidade de utilização do Kit de Adrenalina

\section{Antecedentes pessoais de doença alérgica}

Asma $\square$ Outra:

Notificador: (nome)

Data de Preenchimento: I I (dia/mês/ano)

Contacto: (preferencialmente e-mail)

Enviar para: $\quad$ SPAIC - Sociedade Portuguesa de Alergologia e Imunologia Clínica R. Manuel Rodrigues da Silva, 7C - Escritório 1 1600-503 Lisboa Fax: 217152428 e-mail: spaic@sapo.pt 